\title{
Optimisation of topical antibacterial preparation from Malaysian kelulut honey by using xanthan gum as polymeric agent
}

\author{
Mohd-Aspar, M.A. ${ }^{1}$, Edros, R. ${ }^{1,2^{*}}$, Hamzah, N.A. ${ }^{3}$ \\ ${ }^{1}$ Centre of Excellence for Advanced Research in Fluid Flow, Universiti Malaysia Pahang, Lebuhraya Tun Razak, 23600 Kuantan, Pahang, Malaysia \\ ${ }^{2}$ Faculty of Chemical \& Process Engineering Technology, Universiti Malaysia Pahang, Lebuhraya Tun Razak, 23600 Kuantan, Pahang, Malaysia \\ ${ }^{3}$ The Pathology and Laboratory Medicine Department, Sultan Ahmad Shah Medical Centre, 25200 Kuantan, Pahang, Malaysia \\ *Corresponding author: rzahirah@ump.edu.my
}

\section{ARTICLE HISTORY}

Received: 8 October 2020 Revised: 30 May 2021

Accepted: 31 May 2021

Published: 31 July 2021

\begin{abstract}
The study aims to formulate and optimise topical antibacterial preparation by using Malaysian kelulut honey as the active ingredient and xanthan gum as the polymeric agent. Response surface methodology was used to optimise the preparation. The acidity, honey concentration and xanthan gum concentration were the independent variables. The zone of inhibitions on S. aureus ATCC6538 and E. coli ATCC8739 were the response variables. The optimal preparation was evaluated on its physicochemical properties, viscosity, antibacterial efficacy and stability. The antibacterial efficacy of the optimal preparation was compared to the commercially antibacterial gel (MediHoney ${ }^{\mathrm{TM}}$, Comvita). The optimal preparation was formulated at $\mathrm{pH}$ of 3.5 , honey concentration of $90 \%(\mathrm{w} / \mathrm{v})$ and xanthan gum concentration of $1.5 \%(\mathrm{w} / \mathrm{v})$ with the inhibition zones measured on S. aureus ATCC6538 was $16.2 \mathrm{~mm}$ and E. coli ATCC8739 was $15.8 \mathrm{~mm}$ respectively. The factors of acidity and honey concentration have significantly influenced the inhibition zone on S. aureus ATCC6538 and E. coli ATCC8739. The utilisation of xanthan gum as the polymeric agent was fit for the preparation which showed by adequate physicochemical properties and retained of the antibacterial effects. This was supported by constant viscosity and efficacy of the preparation within the six months of stability study indicating stable and reliable preparation. Xanthan gum is a potential polymeric agent due to its effective use in preparing stable preparation with effective antibacterial properties.
\end{abstract}

Keywords: Antibacterial properties; optimisation; Malaysian kelulut; topical preparation; xanthan gum.

\section{INTRODUCTION}

Honey has been known as an effective antibacterial agent to prevent bacterial infection (Khalil et al., 2014) with the presence of both bacteriostatic and bactericidal effects. The potent antibacterial properties of honey was effective against laboratory standard bacteria such as ATCC (Chua \& Ismail, 2015; Almasaudi et al., 2017) and also those obtain from clinical isolation (Johnston et al., 2018; Kateel et al., 2018). There are numerous honey harvested from various countries including New Zealand (Weston et al., 1999), Australia (Irish et al., 2011), Italy (Grego et al., 2016), Brazil (Sousa et al., 2016), Saudi Arabia (Zakaria, 2015), and Taiwan (Liu et al., 2013) have been studied on its used to prevent bacterial infection. Among the honey, the manuka honey that is native to New Zealand (Johnston et al., 2018) and Australia (Carter et al., 2016) is known to possess potent antibacterial properties.

In Malaysia, there are honey such as tualang, kelulut and acacia have been identified to possess beneficial bioactive properties including antibacterial (Tan et al., 2009; Syazana et al., 2013; Zainol et al., 2013; Ismail, 2016; Ranneh et al., 2018). Among the Malaysian honey, kelulut was being studied and found to own potent antibacterial properties including bacteriostatic and bactericidal effects (Jalil et al., 2017; Tuksitha et al., 2018; Yaacob et al., 2018). Interestingly, in our recent study, it was revealed that kelulut has a higher antibacterial properties as compared to manuka against the common pathogenic bacteria species such as $P$. aeruginosa (Mohd-aspar \& Edros, 2019; Mohd et al., 2020a, 2020b). Although Malaysian kelulut honey has been reported to possess potent antibacterial properties, until now, there are only limited studies that have reported on utilisation of kelulut honey as an alternative to prevent bacterial infection. Instead, the usage of Malaysian honey are limited to medicinal tonic for health consumption (Ismail, 2016). The development progress on such local honey is still unsatisfied thus demanding more efforts to discover more pharmacological properties and applications. 
Based on the presence of antibacterial properties, honey has been successfully applied as a topical preparation in the treatment of wound infection (Mohd-aspar et al., 2021). Other than antibacterial properties, the additional characteristics of honey such as non-irritant, non-toxic, selfsterile, nutritive, and easily applied (Boukraâ, 2014; Ismail, 2016) enhanced its potential to be effectively utilised as a topical antibacterial agent. Based on the tropical rainforest, the honey harvested in Malaysia contained high moisture content (exceeding 20\%) which is less viscous and unsuitable to be directly applied without improvement on its rheological properties. The honey could not remain on the site of action as long as needed and maintain the concentration within the effective range to promote bacteriostatic and bactericidal effects (El-kased et al., 2017; Zhu et al., 2019).

Polysaccharides derived from natural gums such as xanthan gum is widely used as polymeric agent due to its biodegradability and non-toxic characteristics (Badwaik et al., 2013; Benny et al., 2014; Thombare et al., 2016). Xanthan gum is a high molecular weight polysaccharide produced predominantly by Xanthomonas campestris in an aerobic condition from sugar cane, corn or their derivatives (Badwaik et al., 2013). These natural polysaccharides give highly viscous solution even at $1 \%$ of the aqueous dispersion of the gum. Xanthan gum is used mainly as a thickener in food, cosmetic, and pharmaceutical industries (Garcia-Ochoa et al., 2000; Bueno et al., 2013; Benny et al., 2014).

In the effort to implement the Malaysian honey as an antibacterial agent, the study aims to evaluate the potential development of a topical preparation from Malaysian kelulut honey with the employment of xanthan gum as the polymeric agent. The rheological properties of Malaysian honey were aimed to be improved by using the natural xanthan gum as thickening agent. In order to maximise the effect on preventing the growth of bacteria, the preparation was optimised through response surface method by considering the most effective $\mathrm{pH}$, honey concentration and polymeric agent concentration used. The optimal preparation was evaluated on its physicochemical properties, antibacterial efficacy, and stability to affirm on the stability and adequacy of the formulated preparation. As for antibacterial efficacy, the commercially available antibacterial gel (MediHoney ${ }^{\mathrm{TM}}$ ) was used as a basis of comparison.

\section{MATERIALS AND METHODS}

\section{Honey Samples}

Kelulut samples were obtained from local apiarist and aseptically stored in the sterile bottles. The information of the collected honey were recorded in the form of certificate of analysis ( $C O A)$ that has been accredited by Malaysian Agriculture Research and Development Institute (MARDI). Additional assay by using the RapidRaw ${ }^{\mathrm{TM}}$ method, which was developed by the Malaysia Genome Institute (MGI) was included to verify the purity of honey. Honey that has not been processed contains more natural compounds to react with the reagents which resulted with formation of sediment. The honey without visible sediment are processed honey. The kelulut sample used in this study showed clear visible sediment indicating the purity of honey. This is in agreement with our negative control with the sole presence of sugar substance. The honey were stored in sterile glass bottles for experimental works and kept in the dark plastic container away from direct sunlight at room temperature.

\section{Materials and Methods}

The xanthan gum was purchased from Sigma, US. Sodium benzoate and triethanolamine (TEA) were purchased from Bendosen, Malaysia.

\section{Bacteria}

The study has employed eight standard strains and fourteen clinically isolated strains of common bacteria infecting wound. The eight standard strain bacteria were kindly supplied by the Department of Pathology \& Laboratory Medicine, International Islamic University Malaysia Medical Centre (IIUMMC) and Central Laboratory Universiti Malaysia Pahang (UMP) and labelled as standard strains of American Type Culture Collection (ATCC, US). These includes three grampositive bacteria of Staphylococcus aureus ATCC 6538, Streptococcus pyogenes ATCC 19615 and Enterococcus faecalis ATCC 29212, and five gram-negative bacteria of Escherichia coli ATCC 8739, Pseudomonas aeruginosa ATCC 9027, Salmonella typhimurium ATCC 14028, Proteus mirabilis ATCC 12453, and Klebsiella pneumonia ATCC BAA 1144. The 14 clinically isolated bacteria were obtained primarily from Department of Pathology \& Laboratory Medicine, International Islamic University Malaysia Medical Centre (IIUMMC). These include five grampositive bacteria of Staphylococcus aureus, Staphylococcus hominis, Staphylococcus haemolyticus, Streptococcus pyogenes, and Streptoccocus agalactiae and another nine gram-negative bacteria of Escherichia coli, Pseudomonas aeruginosa, Salmonella sp., Proteus mirabilis, Proteus vulgaris, Klebsiella pneumonia, Acinetobacter baumannii, Enterobacter cloacae, and Enterococcus aerogenes. The bacteria were re-cultured in a nutrient or soy agar and incubated at $37^{\circ} \mathrm{C}$ for 24 hours in which by then is known as primary culture.

\section{Preparation of Working Bacteria}

Working bacterial culture was prepared by inoculating a loop of primary culture into sterile screw-capped test tubes containing $10 \mathrm{ml}$ of broth and incubated in a shaking incubator for 24 hours at a temperature of $37^{\circ} \mathrm{C}$ and rotational speed of $150 \mathrm{rpm}$. The prepared working bacteria cultures were adjusted to $0.5 \mathrm{McF}$ arland standard which equivalent to $1.5 \times 10^{8} \mathrm{CFU} / \mathrm{mL}$. It was prepared based on optical density by diluting the working bacteria into fresh sterile broth and adjusted to the absorbance range of 0.08 to 0.13 (Franklin et al., 2012). The absorbance of prepared cultures was measured by using UV-viscometer (Shimadzu, Japan) at the reference wavelength of $600 \mathrm{~nm}$.

\section{Preparation of the Topical Preparation}

The preparation with kelulut honey was prepared by employing the cold mechanical method (El-kased et al., 2017) in which the desired amount of natural polymer was dissolved in the sterile deionised water with continuous stirring for $1 \mathrm{~h}$ until the polymer was completely soaked in water. This step was followed by the addition of $0.02 \%(\mathrm{w} / \mathrm{v})$ sodium benzoate (Bendosen, Malaysia) as a preservative in the preparation. Sodium benzoate is a commonly used as preservative agent especially in food products due to its non-toxic and safe additive (Shahmihammadi et al., 2016), with the allowed amount of usage of $0.03 \%(w / w)$ by FDA (Pongsavee, 2015). The mixture was stirred continuously for $30 \mathrm{~min}$. The desired amount of honey was added to the mixture with continuous stirring for another $30 \mathrm{~min}$ until the honey was dissolved. The final volume of each preparation was set to $100 \mathrm{~mL}$ by adding sterile deionised water. The preparation was kept in a sterile, wide-mouth glass 
container that was covered with a lid and stored at $28^{\circ} \mathrm{C}$ for $24 \mathrm{~h}$ for a complete swelling.

\section{Measurement of Inhibition Zone}

Prior to investigating the potency to inhibit bacteria growth, a study was conducted to measure the zone of inhibition on the bacterial strains when exposed to the preparation. This was performed qualitatively by using the agar well diffusion assay as previously described (Sherlock et al., 2010; Moussa et al., 2012) to gain an understanding of the sensitivity of bacteria towards the preparation. In this assay, two types of agars were used, i.e., nutrient agar and soy agar depending on the bacteria. Soy agar was used to grow E. faecalis and $S$. pyogenes, while nutrient agar was used to grow S. aureus, $E$. coli, $P$. aeruginosa, S. typhimurium, P. mirabilis and $K$. pneumonia. The nutrient and soy agar were prepared by dissolving $23 \mathrm{~g}$ and $40 \mathrm{~g}$ of agar to $1 \mathrm{~L}$ of distilled water and later autoclaved at the pressure of $100 \mathrm{kPa}$ and temperature of $121^{\circ} \mathrm{C}$ for 20 min. The agars were allowed to cool down slightly and was poured into $90 \mathrm{~mm} \times 15 \mathrm{~mm}$ (Brandon ${ }^{\mathrm{TM}}$, Malaysia) petri dishes.

The working bacterial culture, which was adjusted to 0.5 McFarland bacteria concentration, was prepared as described previously. A volume of $100 \mu \mathrm{L}$ of the adjusted 0.5 McFarland culture was spread onto the agar by using the spread plate technique. Upon inoculation, $6 \mathrm{~mm}$ diameter wells were cut on the agar surface. A plate was divided into four quadrants, where a single well was created in each quadrant to contain $80 \mu \mathrm{L}$ of the preparation. Plates were incubated at $37^{\circ} \mathrm{C}$ for $24 \mathrm{~h}$. The diameters of inhibition zones were measured by using a ruler in millimetres $(\mathrm{mm})$ based on the diameter of circles formed around the tested well areas in which the bacterial colonies do not grow. This diameter is inclusive of the diameter of the $6 \mathrm{~mm}$ well that was used to occupy the tested preparation. The commercially available topical gel was used as a positive control. Based on the inhibition zones measured, the sensitivity of bacteria towards preparation was categorised as not sensitive, sensitive, very sensitive, and extremely sensitive as previously described (Moussa et al., 2012). The not sensitive was denoted by the diameter of inhibition zone of lower than $8 \mathrm{~mm}$, sensitive for the diameter from 8 to $14 \mathrm{~mm}$, very sensitive for the diameter from 15 to $19 \mathrm{~mm}$, and extremely sensitive for the diameter of $20 \mathrm{~mm}$ and above.

\section{Design of Response Surface Methodology}

In RSM, the experimental domain is defined as the antibacterial properties of the preparation. Three independent variables were $\mathrm{pH}$, honey concentrations $(\%, \mathrm{w} / \mathrm{v})$, and polymeric agent concentrations $(\%, w / v)$, and designated as $X_{1}, X_{2}$, and $X_{3}$, respectively. The inhibition zone $(\mathrm{mm})$ on S. aureus ATCC 6538, and E. coli ATCC 8739 were collected as the response variables which were designated as $Y_{1}$ and $Y_{2}$, respectively. The bacteria of $S$. aureus and $E$. coli were selected since these species were commonly isolated from an infected wound and have various mechanisms of resistance toward antibacterial agents, such as biofilm formation (Jefferson, 2004), active beta-lactamase production (Brudzynski \& Sjaarda, 2014; Peacock \& Paterson, 2015), and high pH tolerance (Molan, 1992; Cotter \& Hill, 2003).

In each of the independent variables $X_{1}, X_{2}$, and $X_{3}$, the optimum parameters were determined within the range that were set during the optimisation work. The lowest value was referred as low level and the highest value was referred as the high level respectively (Shahzad et al., 2012; Shekar et al., 2014). In this study, the low and high levels were set between 3.5 and 6.5 for acidity $\left(X_{1}\right), 50 \%$ and $90 \%(\mathrm{w} / \mathrm{v})$ for honey concentration $\left(X_{2}\right)$ and $1.0 \%$ and $2.0 \%(\mathrm{w} / \mathrm{v})$ for the xanthan gum concentration $\left(X_{3}\right)$ respectively. The low and high levels of the independent variables were set according to the literature.

In this study, RSM by using the central composite design (CCD) was used to optimise the antibacterial properties of the preparation. According to the CCD, the total number of experimental combinations is based on Equation 1 below (Shekar et al., 2014; Anitha \& Pandey, 2016):

$$
2^{k}+2 k+n_{0} \quad \text { Equation [1] }
$$

Where $k$ is the number of independent variables and $n_{0}$ is the number of repetitions of the experiments at the central points. In this study, three independent variables were involved $(k=3)$ with five replicates at the centre points $\left(n_{0}=5\right)$ leading to a total of nineteen runs.

The Design of Experts Software (DOE version, 7.1.3, STATEASE Inc., Minneapolis, USA) was used for Analysis of Variance (ANOVA), regression, and graphical analyses of the data obtained. The desirability function to get the optimum combinations of independent variables was fitted by the least square method using the software. The threedimensional response graph and profile for predicted values and desirability level for independent variables were plotted by employing the same software. In ANOVA, the analysis included overall model significance, correlation coefficient $(R)$, and determination coefficient $\left(R^{2}\right)$ that measure the goodness of fit of the regression model.

\section{Evaluation of the Optimal Preparation}

The optimal preparation resulting from each optimisation process were evaluated in terms of physicochemical properties, antibacterial efficacy, and stability. This is essential in order to decide on adequate and reliable preparation.

\section{Physicochemical Properties}

The physicochemical properties of the optimal preparation was evaluated in term of physical appearance, colour, homogeneity, grittiness, lump formation, viscosity, and $\mathrm{pH}$. The viscosity was measured by using Viscometer VL210001 (Fungilab, Spain), spindle number R5, at 100 rotations per min. The $\mathrm{pH}$ was measured by using the $\mathrm{pH}$ meter SevenCompact ${ }^{\mathrm{TM}}$ (Mettler Toledo, USA).

\section{Centrifugation Test}

The centrifugation test was performed by using a refrigerated centrifuge 5810R (Eppendorf, Germany) as previously described by (Dantas et al., 2016). It was done by adding $10 \mathrm{~g}$ of the preparation in a tapered test tube and was subjected to a cycle of $3000 \mathrm{rpm}$ for $30 \mathrm{~min}$ at the room temperature of $25^{\circ} \mathrm{C}$.

\section{Antibacterial Efficacy}

The antibacterial efficacy of the optimal preparation was evaluated by using two separate methods. The first method was the evaluation on the inhibition effect by using the measurement of inhibition zone and the second method was the evaluation on the bactericidal effect by using the tube dilution method. For both evaluations, the experiments were performed on 22 bacterial species, including eight standard strains and fourteen clinical strains as previously listed. 


\section{Measurement of Inhibition Zone}

The ability of the preparation to inhibit the growth of wound-associated bacteria was determined through the measurement of inhibition zone by using agar well diffusion assay as previously described (Measurement of inhibition zone). The diameters of each inhibition zone was measured in millimetres $(\mathrm{mm})$, including the diameter of well created. Each test was carried out in triplicate, and the average values were calculated.

\section{Bactericidal Effect}

The bactericidal effect of the optimal preparation was determined by using tube dilution method as previously described (Shagana \& Geetha, 2017). An equal volume of 0.5 $\mathrm{mL}$ of the preparation was mixed with $0.5 \mathrm{~mL}$ of freshly prepared broth in screw cap tube (Jain et al., 2016; Shagana \& Geetha, 2017). Then, a loopful of the test organism that has been adjusted to $0.5 \mathrm{McF}$ arland was transferred into the tube (Dewanjee et al., 2008). A tube that contained $1 \mathrm{~mL}$ of freshly prepared broth and seeded with a loopful of test organism was used as a control. The prepared tubes were then incubated in the incubator shaker at $37^{\circ} \mathrm{C}$ at a rotational speed of $150 \mathrm{rpm}$ for $24 \mathrm{~h}$. After overnight incubation, a loopful suspension was suspended and inoculated onto freshly prepared TSA by using the streak plate method. Then, the plate was incubated for another $24 \mathrm{~h}$ in $37^{\circ} \mathrm{C}$ before being observed for any bacterial growth. A plate with no visible growth of bacteria was considered to possess bactericidal effect while the plate with the visible formation of bacterial colony was considered as the absence of a bactericidal effect.

\section{Stability Study}

Evaluation of the stability of the optimal preparation was adapted from previous studies (Chen et al., 2016; Dantas et al., 2016; Majumdar et al., 2018) with slight modification. The preparation was kept in the glass containers and stored in long-term and accelerated conditions, which were at $25^{\circ} \mathrm{C} \pm$ $2 / 60 \% \pm 5 \mathrm{RH}$ and $40^{\circ} \mathrm{C} \pm 2 / 75 \% \pm 5 \mathrm{RH}$, respectively for six months and evaluated at $0,1,2,3$, and 6 months. The storage conditions during the stability study were set according to the ICH guideline (World Health Organisation, 2018). The evaluations were observed based on colour, $\mathrm{pH}$, homogeneity, viscosity, and antibacterial efficacy, which were conducted similar to the procedures described in the previous sections. In the measurement of the inhibition zone and bactericidal effect, three Gram-positive i.e., S. aureus ATCC 6538, E. faecalis ATCC and S. pyogenes and three Gram-negative i.e., E. coli ATCC 8739, K. pneumonia and E. aerogenes were considered.

\section{RESULTS AND DISCUSSION}

\section{Response Surface Methodology (RSM) for the Preparation}

The nature of kelulut honey is less viscous which unsuited to be applied topically as it could not remain on the site of action as long as needed and maintain the concentration within the effective range to promote bacteriostatic and bactericidal effects. Due to its incompatibility, kelulut honey has been prepared as a preparation. The natural polymers i.e., xanthan gum was used to improve the rheological properties of the honey to make it topically applicable. The optimisation through Response Surface Methodology (RSM) has been employed to optimise the preparation for prevention of bacterial infection. The optimal independent variable i.e., acidity $\left(X_{1}\right)$, concentration of honey $\left(X_{2}\right)$ and concentration of xanthan gum $\left(X_{3}\right)$ were determined with respond to the diameter of the inhibition zones on $S$. aureus
Table 1. Experimental design of the central composite design and response for the experimental runs

\begin{tabular}{|c|c|c|c|c|c|}
\hline \multirow{2}{*}{ Run } & \multicolumn{3}{|c|}{ Factor } & \multicolumn{2}{|c|}{ Response of inhibition zone $(\mathrm{mm})$} \\
\hline & $\mathrm{X}_{1}$ & $\mathrm{X}_{2}$ & $\mathrm{X}_{3}$ & S. aureus $\left(\mathrm{Y}_{1}\right)$ & E. coli $\left(\mathrm{Y}_{2}\right)$ \\
\hline 1 & 3.50 & 50.00 & 1.00 & $11.7 \pm 0.58$ & $11.3 \pm 0.58$ \\
\hline 2 & 6.50 & 50.00 & 1.00 & $7.8 \pm 0.00$ & $8.0 \pm 0.29$ \\
\hline 3 & 3.50 & 90.00 & 1.00 & $13.8 \pm 0.29$ & $13.7 \pm 0.58$ \\
\hline 4 & 6.50 & 90.00 & 1.00 & $8.0 \pm 0.00$ & $8.3 \pm 0.58$ \\
\hline 5 & 3.50 & 50.00 & 2.00 & $12.2 \pm 0.29$ & $10.7 \pm 0.58$ \\
\hline 6 & 6.50 & 50.00 & 2.00 & $8.0 \pm 0.00$ & $8.3 \pm 0.58$ \\
\hline 7 & 3.50 & 90.00 & 2.00 & $13.8 \pm 0.29$ & $12.3 \pm 0.29$ \\
\hline 8 & 6.50 & 90.00 & 2.00 & $9.0 \pm 1.00$ & $8.3 \pm 0.58$ \\
\hline 9 & 2.48 & 70.00 & 1.50 & $16.2 \pm 0.58$ & $15.8 \pm 0.58$ \\
\hline 10 & 7.52 & 70.00 & 1.50 & $8.3 \pm 0.58$ & $8.3 \pm 0.58$ \\
\hline 11 & 5.00 & 36.36 & 1.50 & $7.8 \pm 0.00$ & $7.8 \pm 0.58$ \\
\hline 12 & 5.00 & 103.64 & 1.50 & $9.7 \pm 0.58$ & $9.5 \pm 0.00$ \\
\hline 13 & 5.00 & 70.00 & 0.66 & $8.3 \pm 0.58$ & $8.5 \pm 0.58$ \\
\hline 14 & 5.00 & 70.00 & 2.34 & $9.0 \pm 0.00$ & $9.2 \pm 0.58$ \\
\hline 15 & 5.00 & 70.00 & 1.50 & $8.7 \pm 0.76$ & $8.7 \pm 0.50$ \\
\hline 16 & 5.00 & 70.00 & 1.50 & $9.2 \pm 0.29$ & $9.2 \pm 0.29$ \\
\hline 17 & 5.00 & 70.00 & 1.50 & $8.7 \pm 0.76$ & $9.0 \pm 0.29$ \\
\hline 18 & 5.00 & 70.00 & 1.50 & $8.8 \pm 0.76$ & $9.0 \pm 0.50$ \\
\hline 19 & 5.00 & 70.00 & 1.50 & $8.8 \pm 0.29$ & $9.2 \pm 0.76$ \\
\hline
\end{tabular}

The symbol \pm represents the standard deviation, which was calculated between the three biological replicates. Student's t-test shows significant differences for the data collected $(P$-value $<0.05)$.

ATCC $6538\left(Y_{1}\right)$ and E. coli ATCC $8739\left(Y_{2}\right)$. The results for optimisation of preparation by using xanthan gum were described below.

\section{Analysis of Variance (ANOVA) and Model Fitting}

A total of 19 experimental runs were conducted which combined different levels of independent variables (Shekar et al., 2014; Anitha \& Pandey, 2016). The observed responses from each run are tabulated in Table 1.

Based on the findings, the diameter of inhibition zones measured were found to range from $7.8 \pm 0.00 \mathrm{~mm}$ to $16.2 \pm$ $0.58 \mathrm{~mm}$ on $S$. aureus and $7.8 \pm 0.58 \mathrm{~mm}$ to $15.8 \pm 0.58 \mathrm{~mm}$ on E. coli, respectively. The largest zones of inhibition of $16.2 \pm$ $0.58 \mathrm{~mm}$ and $15.8 \pm 0.58 \mathrm{~mm}$ were measured on $S$. aureus and E. coli, respectively in run number 9 , while the smallest zones of inhibition of $7.8 \pm 0.00 \mathrm{~mm}$ and $7.8 \pm 0.58 \mathrm{~mm}$ were measured on $S$. aureus and $E$. coli, respectively in run number 11 .

A second-order polynomial model was developed by using RSM for the prediction of optimum responses in a function of independent variables and their interactions (Ammer et al., 2016). It was performed by applying multiple regression analysis on the experimental data. Based on the generated model, the role of each independent variable $\left(X_{1}\right.$, $X_{2}$, and $X_{3}$ ) and their interaction can be explained and the optimum zone of inhibition that corresponds to the optimum levels of $\mathrm{pH}$, honey concentration, and xanthan gum concentration can be estimated (Madiha et al., 2017). The second-order polynomial model generated and their estimated regression coefficients are shown in the following equation:

$$
\begin{array}{rlr}
Y_{1}= & 8.82-2.34 X_{1}+0.59 X_{2}+0.21 X_{3}-0.31 X_{1} X_{2}+0.088 X_{1} X_{3}+ & \\
& 0.038 X_{2} X_{3}+1.33 X_{1}^{2}+0.094 X_{2}^{2}+0.059 X_{3}^{2} & \text { Equation [2] } \\
Y_{2}= & 9.01-2.03 X_{1}+0.52 X_{2}-0.038 X_{3}-0.46 X_{1} X_{2}+ & \\
& 0.29 X_{1} X_{3}-0.14 X_{2} X_{3}+1.12 X_{1}^{2}-0.086 X_{2}^{2}-0.015 X_{3}^{2} & \text { Equation [3] }
\end{array}
$$


Where $Y_{1}$ and $Y_{2}$ are the responses, i.e., the inhibition zones on $S$. aureus and E. coli, respectively. $X_{1}, X_{2}$, and $X_{3}$ are the coded values of the independent variables, i.e., $\mathrm{pH}$, honey concentration, and xanthan gum concentration, respectively.

In general, both Equation 2 and Equation 3 consist of three linear terms $\left(X_{1}, X_{2}\right.$, and $\left.X_{3}\right)$, three quadratic terms $\left(X_{1}{ }^{2}\right.$, $x_{2}{ }^{2}$, and $X_{3}{ }^{2}$ ), and three combinations of two factorial terms $\left(X_{1} X_{2}, X_{1} X_{3}\right.$, and $\left.X_{2} X_{3}\right)$ to explain the role of independent variables $\left(X_{1}, X_{2}\right.$, and $\left.X_{3}\right)$ that affect response variables $\left(Y_{1}\right.$ and $Y_{2}$ ). The positive coefficients indicate a linear effect which is directly proportional to the zone of inhibition while the negative coefficients show a negative effect that is inversely proportional to the zone of inhibition (Wang et al., 2011; Shahzad et al., 2012).

From both equations, the effect of $\mathrm{pH}\left(X_{1}\right)$ is more pronounced compared to honey concentration $\left(X_{2}\right)$ and xanthan gum concentration $\left(X_{3}\right)$ since the coefficient of $X_{1}$ is 2.34, which is 4 -fold and 11 -fold higher than the coefficient of $X_{2}$ and $X_{3}$ with values of 0.59 and 0.21 , respectively for Equation 2. This also applies to Equation 3 with a value of 2.03 for $X_{1}$, which is 4 -fold and 53-fold higher compared to $X_{2}$ and $X_{3}$ with values of 0.52 and 0.038 , respectively.

The significant impact of each term in the second-order polynomial equation was evaluated through ANOVA and the results are tabulated in Table 2 . The degree of significance for every term in the equation including linear $\left(X_{1}, X_{2}, X_{3}\right)$, quadratic $\left(X_{1}{ }^{2}, X_{2}{ }^{2}, X_{3}{ }^{2}\right)$, and combination $\left(X_{1} X_{2}, X_{1} X_{3}\right.$ and $\left.X_{2} X_{3}\right)$ were analysed at $95 \%$ confident interval $(P$-value $<0.05)$ (Ammer et al., 2016; Madiha et al., 2017).

Among the linear terms, the main effect of $\mathrm{pH}\left(X_{1}\right)$ and honey concentration $\left(X_{2}\right)$ on inhibition zones of both $S$. aureus and $E$. coli were highly significant as proven by their respective $P$-values with $P_{X 1}<0.0001$ and $P_{X 2}=0.0005$ for $S$. aureus, and $P_{X 1}$ $<0.0001$ and $P_{X 2}=0.0007$ for $E$. coli, respectively. In contrast, xanthan gum concentration $\left(X_{3}\right)$ has an insignificant effect on inhibition zones for both $S$. aureus and $E$. coli with $P_{X 3}=$ 0.0894 and $P_{X 3}=0.7205$, respectively. For quadratic terms, only $X_{1}{ }^{2}$ was significant at $5 \%$ level with $P_{X_{1}}<0.0001$ for both S. aureus and E. coli. Meanwhile, $X_{2}^{2}$ and $X_{3}^{2}$ were insignificant with $P_{X 2}{ }^{2}=0.4171$ and $P_{X 3}{ }^{2}=0.6081$ for $S$. aureus, and $P_{X 2}{ }^{2}=0.4305$ and $P_{X 3}{ }^{2}=0.8891$ for E. coli, respectively. For combined variables, none of the terms had a significant effect on the zones of inhibition. The results suggested that $\mathrm{pH}$ and honey concentration have a direct relationship with inhibition zones since small variations in their values will considerably

Table 2. Analysis of variance (ANOVA) of the quadratic model and coefficient of determination $\left(R^{2}\right)$ of the quadratic model

\begin{tabular}{|c|c|c|c|c|}
\hline \multirow[t]{2}{*}{ Factors } & \multicolumn{2}{|c|}{ Inhibition zone on S. aureus } & \multicolumn{2}{|c|}{ Inhibition zone on $E$. coli } \\
\hline & $P$-value & Model term & $P$-value & Model term \\
\hline$x_{1}$ & $*<0.0001$ & Significant & $<0.0001$ & Significant \\
\hline$x_{2}$ & $* 0.0005$ & Significant & 0.0007 & Significant \\
\hline$x_{3}$ & 0.0894 & Not Significant & 0.7205 & Not Significant \\
\hline$X_{1} X_{2}$ & 0.0590 & Not Significant & 0.0077 & Not Significant \\
\hline$X_{1} X_{3}$ & 0.5601 & Not Significant & 0.0628 & Not Significant \\
\hline$x_{2} X_{3}$ & 0.8012 & Not Significant & 0.3365 & Not Significant \\
\hline$x_{1}^{2}$ & $*<0.0001$ & Significant & $<0.0001$ & Significant \\
\hline$x_{2}^{2}$ & 0.4171 & Not Significant & 0.4305 & Not Significant \\
\hline$x_{3}^{2}$ & 0.6081 & Not Significant & 0.8891 & Not Significant \\
\hline Model & $*<0.0001$ & Significant & $<0.0001$ & Significant \\
\hline Lack of fit & 0.0507 & Not significant & 0.0620 & Not significant \\
\hline$R^{2}$ & \multicolumn{2}{|c|}{0.9860} & \multicolumn{2}{|c|}{0.9839} \\
\hline Adjusted $R^{2}$ & \multicolumn{2}{|c|}{0.9860} & \multicolumn{2}{|c|}{0.9678} \\
\hline
\end{tabular}

Significant at $5 \%$ level $(P$-value $<0.05)$. alter the zones of inhibition for both S. aureus and E. coli. This is consistent with a study conducted previously in which $\mathrm{pH}$ and honey concentration have a strong influence on antibacterial properties of honey (Johnston et al., 2018; Kateel et al., 2018).

The precision of the quadratic regression model is also supported by the ANOVA results (Wang et al., 2011; Anitha \& Pandey, 2016). From Table 2, the quadratic regression model was highly significant with $P$-value $<0.0001$ for both $S$. aureus and $E$. coli. This indicates that the quadratic regression model as expressed in Equation 2 and Equation 3 provides a suitable model to describe the response of the experiment pertaining to the zone of inhibition (Shahzad et al., 2012). In addition, the model also showed a statistically insignificant lack of fit with $P$-value of 0.0507 and 0.0620 for S. aureus and E. coli respectively, indicating the adequate fit of the models (Shahzad et al., 2012; Shekar et al., 2014; Khuri, 2017).

The model's goodness of fit based on RSM can be further checked by the determination coefficient $\left(R^{2}\right)$ and adjusted $R^{2}$ (Shahzad et al., 2012; Shekar et al., 2014). The $R^{2}$ provides a measure of variability in the observed response values that can be explained by the experimental factors and their interactions. The $R^{2}$ value is always between 0 and 1 , and the closer the $R^{2}$ value to 1 , the stronger the model to predict the response (Mulye et al., 2014; Madiha et al., 2017). An $R^{2}$ value higher than 0.9 indicates a strong correlation (Shahzad et al., 2012). In this study, the coefficient of determination $R^{2}$ were 0.9860 and 0.9839 (Table 2), implying that the zones of inhibition are attributed to the given range of $\mathrm{pH}$, honey concentration, and xanthan gum concentration. The $R^{2}$ also indicates that $98 \%$ of the total variation was explained by the model while only $2 \%$ was not explained which is due to external factors. The values of the adjusted determination coefficient (adjusted $R^{2}=0.9719$ and 09678) were also high, indicating good accuracy and ability of the polynomial model to analyse the response trend (Wang et al., 2011; Ammer et al., 2016). Therefore, it is concluded that the model is adequate to predict the response within the range of variation employed.

\section{Response Surface Analysis}

The interaction between independent variables; $X_{1} X_{2}, X_{1} X_{3}$, and $X_{2} X_{3}$ as indicated in Table 2 can be visualised by using $3 D$ response surface and $2 D$ contour plots as shown in Figure 1 for S. aureus ATCC 6538 and Figure 2 for E. coli ATCC 8739. These plots are important to illustrate the effects of independent variables, and their interactions on the response variables.

Figure 1 (a) and Figure 2 (a) show the 3D plots and their corresponding contour plots, showing the effect of $\mathrm{pH}\left(X_{1}\right)$ and honey concentration $\left(X_{2}\right)$ on inhibition zones of $S$. aureus and $E$. coli, while the concentration of xanthan gum $\left(X_{3}\right)$ was fixed at its middle level which was $1.5 \%(\mathrm{w} / \mathrm{v})$. For both S. aureus and E. coli, at any $\mathrm{pH}$ level between 3.5 and 6.5, honey concentration showed an inverse correlation with the zone of inhibition. As the preparations were prepared at lower $\mathrm{pH}$, the zones of inhibition were increased. In contrast, the honey concentration showed a direct correlation to the zone of inhibition, regardless of which $\mathrm{pH}$ level was employed within $\mathrm{pH} 3.5$ and 6.5. As the concentration of honey increased, the zone of inhibition also increased. The findings indicate acidity has no significant interaction with honey concentration which has proven by the unaffected response of $\mathrm{pH}$ with regards to the concentration of honey and vice versa. The analysis of Figure 1 (a) and Figure 2 (a) reveals that the optimal $\mathrm{pH}$ was at the lowest $\mathrm{pH}$ which was at 3.5 and the honey concentration was at the concentration of $90 \%(w / v)$. 


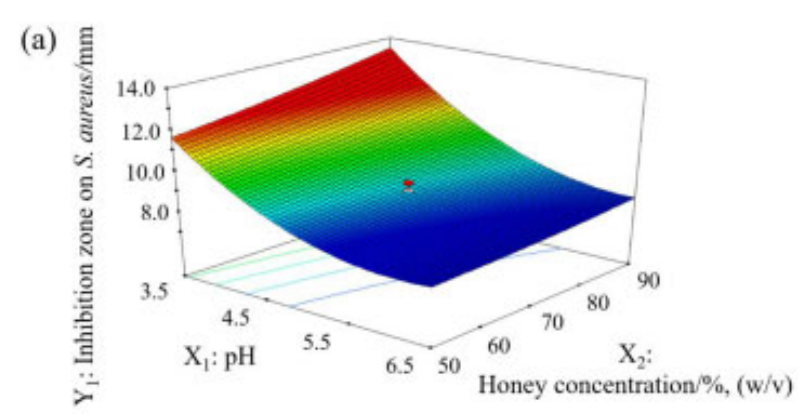

(b)

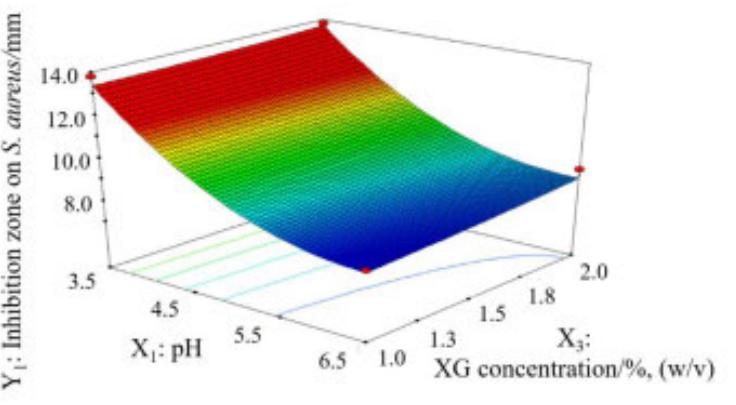

(c)

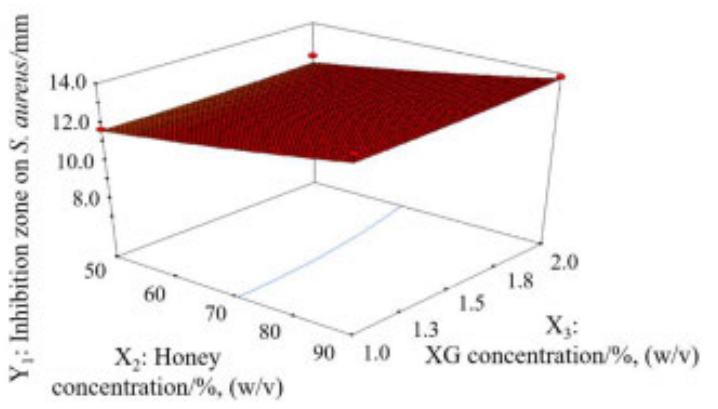

Figure 1. Response surface plot showing the effect of $\mathrm{pH}\left(X_{1}\right)$, honey concentration $\left(X_{2}\right)$, and xanthan gum concentration $\left(X_{3}\right)$ on inhibition zones against $S$. aureus ATCC $6538\left(Y_{1}\right)$. (a) $X_{1} X_{2}$, (b) $x_{1} X_{3}$, and (c) $X_{2} X_{3}$.

Figure 1 (b) and Figure 2 (b) depict the 3D plots and their corresponding contour plots showing the effects of $\mathrm{pH}\left(X_{1}\right)$ and xanthan gum concentration $\left(X_{3}\right)$ on the zones of inhibition of $S$. aureus and $E$. coli, while the honey concentration was fixed at its middle level which was $70 \%(\mathrm{w} / \mathrm{v})$. As the preparation was prepared with xanthan gum concentrations between $1.0 \%$ and $2.0 \%(\mathrm{w} / \mathrm{v})$, the zones of inhibition remained unchanged, regardless of the variation in $\mathrm{pH}$ level. Similarly, as the $\mathrm{pH}$ of the preparation was increased from 3.5 to 6.5 , the zones of inhibition decreased without being affected by the concentration of xanthan gum. According to Figure 1 (b) and Figure 2 (b), it can be observed that there was a lack of interaction between $\mathrm{pH}$ and xanthan gum concentration. The interaction between $\mathrm{pH}\left(X_{1}\right)$ and xanthan gum concentration $\left(X_{3}\right)$ does not give a mutual impact on inhibition zones. No optimal concentration of xanthan gum was observed across the tested range between $1.0 \%$ and $2.0 \%(\mathrm{w} / \mathrm{v})$.

Figure 1 (c) and Figure 2 (c) present the 3D plots and their corresponding contour plots showing the effect of honey concentration $\left(X_{2}\right)$ and xanthan gum concentration $\left(X_{3}\right)$ on the inhibition zones of $S$. aureus and $E$. coli, while the $\mathrm{pH}$ was fixed at its middle level which was 5.0. As the preparation was formulated with xanthan gum concentrations between $1.0 \%$ and $2.0 \%(\mathrm{w} / \mathrm{v})$, the zones of inhibition remained
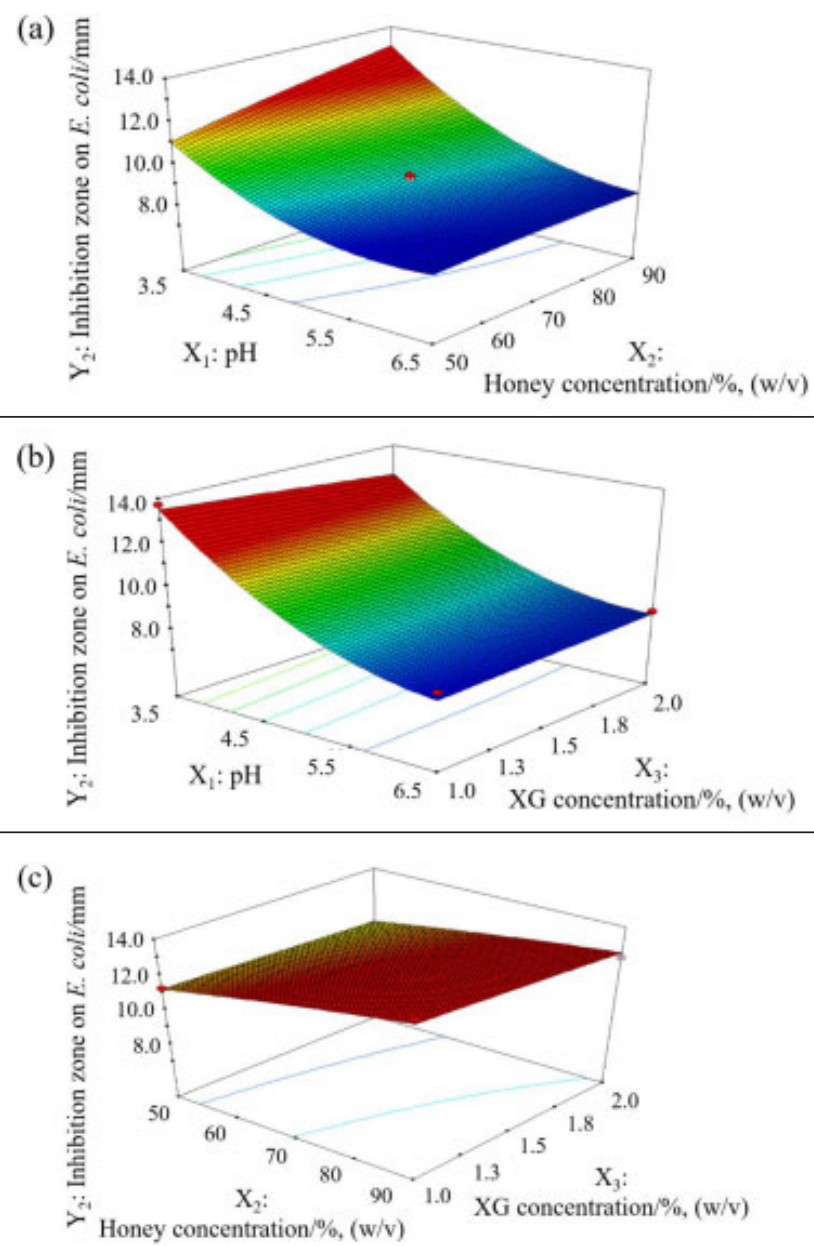

Figure 2. Response surface plot showing the effect of $\mathrm{pH}\left(X_{1}\right)$, honey concentration $\left(X_{2}\right)$, and xanthan gum concentration $\left(X_{3}\right)$ on inhibition zones against $E$. coli ATCC $8739\left(Y_{1}\right)$. (a) $X_{1} X_{2}$, (b) $X_{1} X_{3}$, and (c) $X_{2} X_{3}$.

unchanged. However, as the preparation was formulated with concentrations of honey from $50 \%$ to $90 \%(w / v)$, the zones of inhibition increased in size. The changes in xanthan gum concentration and honey concentration did not show mutual interaction towards the inhibition zones, indicating the lack of interaction between concentrations of honey $\left(X_{2}\right)$ with the concentration of xanthan gum $\left(X_{3}\right)$.

The 3D plots and their respective contour plots are useful to analyse the effect of independent variables towards the response variables and enabled the identification of the optimal response. Based on the results obtained from Figure 1 and Figure 2, the optimal preparation was observed with $\mathrm{pH} 3.5$ and honey concentration of $90 \%(\mathrm{w} / \mathrm{v})$ while the concentration of xanthan gum was chosen at the middle of level which was at $1.5 \%(\mathrm{w} / \mathrm{v})$. This is due to the consistent inhibition zone with less than $5 \%$ of variation across the tested range between $1.0 \%$ and $2.0 \%(\mathrm{w} / \mathrm{v})$.

\section{Verification of the Optimal Responses}

Based on the second-order polynomial models and surface response, the levels of independent variables to produce optimal responses were predicted to be at $\mathrm{pH}$ of 3.5 , honey concentration of $90 \%(\mathrm{w} / \mathrm{v})$ and concentration of xanthan gum of $1.5 \%(w / v)$. According to the RSM analysis, the optimal inhibition zones were estimated to be $13.5 \mathrm{~mm}$ for $S$. aureus 
Table 3. Summary of the predicted and observed responses for the optimal preparation

\begin{tabular}{|c|c|c|c|c|}
\hline Factor & \multicolumn{4}{|c|}{ Optimal value } \\
\hline $\mathrm{pH}$ & \multicolumn{4}{|c|}{3.5} \\
\hline Honey concentration $(\%, w / v)$ & \multicolumn{4}{|c|}{90} \\
\hline Xanthan gum concentration (\%, w/v) & \multicolumn{4}{|c|}{1.5} \\
\hline Response & Predicted & Observed & Residual & Prediction error (\%) \\
\hline Inhibition zone on S. aureus (mm) & 13.5 & 13.7 & \pm 0.2 & 1.5 \\
\hline Inhibition zone on $E$. coli (mm) & 13.1 & 13.9 & \pm 0.8 & 6.1 \\
\hline
\end{tabular}

The symbol \pm represents the standard deviation, which was calculated between three biological replicates.

and $13.1 \mathrm{~mm}$ for $E$. coli respectively. An experiment was carried out to verify the results and the outcomes are tabulated in Table 3.

Based on the conducted experiment, the inhibition zones measured were $13.7 \mathrm{~mm}$ for S. aureus and $13.9 \mathrm{~mm}$ for $E$. coli respectively. The results were in close agreement with the predicted responses with residual percentages of $1.5 \%$ and $6.1 \%$ for $S$. aureus and $E$. coli, respectively. The results confirmed the validity of the predicted models, as the residual percentages were less than 10\% (Shahzad et al., 2012; Madiha et al., 2017).

The RSM is an effective tool for optimising preparation which allows the user to predict the optimal response through the generation of mathematical equations and three-dimensional response surfaces. In preparing a topical preparation, RSM has been used to optimise the percentage of drug release (Mulye et al., 2014), permeability (Shahzad et al., 2012), and spreadability (Mulye et al., 2014). The response to be optimised is selected depending on the main goal of which the preparation has been developed. In the present study, the RSM has been successfully utilised to optimise a preparation that can be topically used to prevent bacterial infection on wound sites. The response variables which were the inhibition zone on $S$. aureus and $E$. coli, have been precisely interpreted in form of mathematical equations and threedimensional response surfaces to assist on the prediction of optimal responses based on the considered independent variables.

In optimising the topical preparation, $\mathrm{pH}$ was one the considered independent variables. The range of $\mathrm{pH}$ between 3.5 and 7.5 was used as it is a suitable range to promote wound healing (Serra et al., 2015). As the preparation was set with the lower $\mathrm{pH}$ i.e., $\mathrm{pH} 3.5$, the inhibition zone measured was noted to increase. This result was found to support the effectiveness of an acidity in preventing bacterial growth (El-kased et al., 2017). The reason for larger inhibition zones in acidic $\mathrm{pH}$ compared to neutral $\mathrm{pH}$ may due to the unsuitable of bacterial growth condition which required $\mathrm{pH}$ between 6.6 to 7.0 (Jones et al., 2015) and also the antimicrobial properties of compounds such as flavonoids and phenolic acids that are available in kelulut honey which reported to increase at lower $\mathrm{pH}$ (Sanchez-Maldonado et al., 2011).

Other than $\mathrm{pH}$, honey concentration was also the considered independent variable in which it was optimised between the concentration of $50 \%$ and $90 \%(w / v)$. As the honey concentration was increased, the diameter of the inhibition zone also increased significantly. This can be explained by the presence of antibacterial compounds such as phenolic acids and flavonoids that increased as the honey concentration increased (Bakar et al., 2017; Tuksitha et al., 2018). In addition, as the honey concentration increased, the degree of sugar content that naturally present in kelulut honey will also increase that can causes dehydration to bacteria (Dluya, 2016). These findings were similar to the previous study that found higher inhibition zone with respond to increments of honey concentration used in honeybased preparation (El-kased et al., 2017).

An ideal topical preparation requires sufficient polymeric cross-link structures to sustain an optimum effect. The concentration of polymer used directly impacts the strength of polymeric cross-links (Wong et al., 2015). The utilisation of xanthan gum at concentrations between $1 \%$ and $2 \%$ were reported to provide sufficient cross-linking strength (Cunha et al., 2005; Bueno et al., 2013; Mulye et al., 2014). Based on the optimisation through RSM, a variation on the concentration of xanthan gum between $1 \%$ and $2 \%$ resulted with no significant effect towards the inhibition zone on both $S$. aureus and $E$. coli and no optimum concentration observed during the optimisation process. The insignificant effect may be due to the use of a narrow range of polymeric agent concentration between $1 \%$ and $2 \%$. Although the range was reported to significantly affect the rheological properties of a preparation (Mulye et al., 2014), however, it does not significantly affect the zone of inhibition.

As the optimal preparation was finalised at a $\mathrm{pH}$ of 3.5 , honey concentration of $90 \%(w / v)$ and xanthan gum concentration of $1.5 \%(\mathrm{w} / \mathrm{v})$, further evaluations on physicochemical properties, antibacterial efficacy, and stability were necessary to ascertain the effective use of the xanthan gum as the polymeric agent in conveying kelulut honey as a topical preparation. Therefore, the description of the outcomes of further evaluations are described in the following sections.

\section{Evaluations of the Optimal Preparation}

Based on the optimal preparation obtained from RSM, the physicochemical properties, antibacterial efficacy, and stability of the optimal preparation was evaluated. The evaluations on physicochemical properties include both physical and chemical characteristics of the preparation, which described the compatibility and reliability of the preparation. Meanwhile, antibacterial efficacy revealed the antibacterial properties the preparation which determined through measurement of inhibition zone and formation of the bacterial colony to specify the bacteriostatic and bactericidal effects. Finally, the stability study was performed to observe the consistency and durability of the preparation upon storage. Within the six months of storage period, the uniformed characteristics with minimal variation on both physical and chemical properties indicate an ideal topical preparation (Hemendrasinh \& Dhruti, 2015; Dantas et al., 2016). 


\section{Physicochemical Properties}

The physicochemical properties of the optimal preparation were evaluated in terms of physical appearance, homogeneity, colour, grittiness, lump formation, $\mathrm{pH}$, viscosity, and centrifugation test. The results are tabulated in Table 4.

The preparation resulted in opaque, homogeneous, and dark brown colour. No grittiness and formation of lump were observed. The $\mathrm{pH}$ of the preparation was recorded at $3.52 \pm$ 0.10 . The $\mathrm{pH}$ recorded can be considered suitable for topical preparation, as the $\mathrm{pH}$ ranging between 2.8 and 7.4 was acceptable for therapeutic effect with non-irritant (Panther \& Jacob, 2015; Dantas et al., 2016;) since the normal pH range of human skin is between 4 to 6 (Schmid-wendtner \& Korting, 2006).

The viscosity of the preparation was measured at $3047 \pm$ $130.1 \mathrm{cps}$. The viscosity was within the range that is sufficient for good spreadability and clarity, as the viscosity that suitable for topical preparation was recorded between 512 and 15000 cps (Singh et al., 2013; Pande et al., 2014; Chen et al., 2016).

The centrifugation test was also conducted to evaluate the gravitational effect on the preparation. This is essential to analyse on adequate quality and stability of the preparation (Dimeski et al., 2011; Iradhati \& Jufri, 2017). Based on the results obtained, no noticeable instability was observed on the preparation upon spinning at $3000 \mathrm{rpm}$ for $30 \mathrm{~min}$ at $25^{\circ} \mathrm{C}$. The preparation remained intact without phase separation indicating adequate and stable formulation (data not shown).

\section{Antibacterial Efficacy}

The antibacterial efficacy of the optimal preparation was evaluated through the measurement of inhibition zone and formation of a bacterial colony. These two evaluations were performed to investigate the sensitivity of bacteria towards the preparation and to examine the ability of the preparation to kill the bacteria. In both evaluations, the preparation was tested on 22 bacterial species associated with wound infection, which include eight standard laboratory (ATCC) and fourteen clinically-isolated bacteria from the wound sites. The commercially available topical antibacterial preparation (MediHoney $^{\mathrm{TM}}$ ) was used as the basis of comparison.

\section{Measurement of Inhibition Zone}

The results for the inhibition zones measured are shown in Figure 3 (a) for Gram-positive and Figure 3 (b) for Gramnegative bacteria. The sensitivity of bacteria towards the preparation was decided according to the range that was previously used.

The range of inhibition zone measured was between $8.5 \pm 0.50 \mathrm{~mm}$ and $17.0 \pm 1.00 \mathrm{~mm}$ which indicate that the bacteria responded between sensitive to very sensitive towards the preparation. In the commercially available preparation by using manuka, the inhibition zone was measured in the range between $8.7 \pm 0.58 \mathrm{~mm}$ and $16.7 \pm 0.58$ $\mathrm{mm}$. The smallest inhibition zone was measured on $K$. pneumonia while the largest was on $S$. agalactiae, respectively. Based on the range of inhibition zone measured, the tested bacteria were responded between sensitive to very sensitive towards the manuka preparation.

In comparing between the optimal preparation and commercially gel, for Gram-positive bacteria (Figure 3 (a)), the optimal preparation showed the highest inhibition zone on three bacteria, including S. aureus ATCC 6538, E. faecalis ATCC 29212, and S. haemolyticus with inhibition zones of $13.7 \pm$ $1.00 \mathrm{~mm}, 12.2 \pm 0.29 \mathrm{~mm}$, and $17.0 \pm 1.00 \mathrm{~mm}$, respectively. These were 1.1-, 1.1-, and 1.2-fold higher as compared to the
Table 4. Physicochemical properties of the optimal preparation

\begin{tabular}{lc}
\hline Formulation & Xanthan gum \\
\hline Physical appearance & Opaque \\
Homogeneity & Homogeneous \\
Colour & Dark brown \\
Grittiness & No \\
Lump formation & No \\
pH & $3.52 \pm 0.10$ \\
Viscosity at 100rpm (cps) & $3047 \pm 130.1$ \\
Centrifugation Test & No phase separation observed
\end{tabular}

The symbol \pm represents the standard deviation which was calculated between three biological replicates.

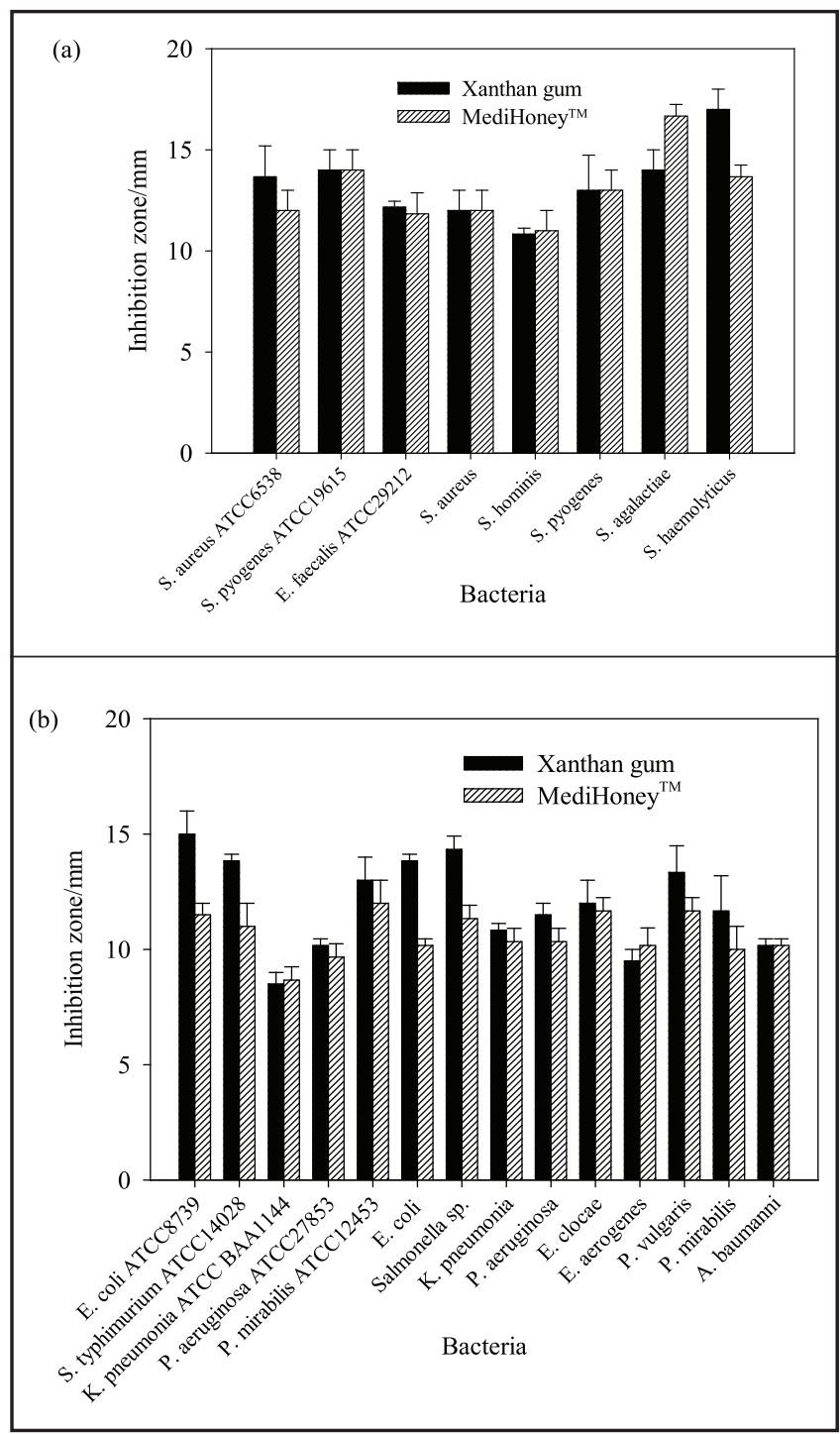

Figure 3. The inhibition zone measured by the preparation tested against the standard laboratory and clinical isolated bacteria of (a) Gram-positive and (b) Gram-negative.

commercially gel. As for Gram-negative bacteria [Figure 3 (b)], out of 14 species, the optimal preparation demonstrated the largest inhibition zone against ten bacteria with an exception on K. pneumonia ATCC BAA 1144, E. cloacae, E. aerogenes, and $A$. baumannii. Based on the results obtained, the optimal preparation was able to be used as a topical 
antibacterial agent which proved by the manifestation of inhibition zone on the tested bacteria.

\section{Bactericidal Effect}

In this section, an attempt was made to investigate on the ability of the preparation to kill the bacteria through formation of bacterial colony. The results were tabulated in Table 5 (a) for Gram-positive and Table 5 (b) for Gramnegative respectively.

In the 22 tested bacteria, no formation of bacterial colony was observed on the surface of agar for the optimal preparation after 24 hours of incubation, indicating the presence of bactericidal effect (Dewanjee et al., 2008; Shagana \& Geetha, 2017). The presence of bactericidal effect for the optimal preparation was observed on the tested Grampositive including S. aureus, E. faecalis ATCC 29212, S. hominis, and S. haemolyticus) and Gram-negative including E. coli, $P$. aeruginosa, Salmonella sp. and $K$. pneumonia) bacteria, respectively. Similar results demonstrated by the preparation of manuka, except on E. faecalis ATCC 29212 which formation of bacterial colonies were observed. In the control sample, which the bacteria was cultured in broth alone, the formation of bacteria colonies were observed for the 22 bacteria indicating the absence of a bactericidal effect.

In many types of acute and chronic wounds, $S$. aureus and $P$. aeruginosa are usually isolated from the infected wounds (Serra et al., 2015; Negut et al., 2018). These bacteria often cause biofilm development and chronic infections which may suppress immune activities and promote the development of antibiotic-resistant strains (Serra et al., 2015). Similar to $S$. aureus and $P$. aeruginosa, other wound-associated bacteria such as E. coli, S. pyogenes, E. faecalis, and P. mirabilis can also develop a biofilm, antimicrobial inactivating enzymes, and other resistance mechanisms to eliminate the antibacterial action (Lu et al., 2014; Kim et al., 2018). In this study, 22 wound associate bacteria which include standard laboratory and clinical strains that isolated from infected wounds have been tested and were found to be susceptible to the preparation. This was proven by the formation of inhibition zone and the presence of bactericidal effect for the optimal preparation against the tested bacteria. The results indicate that the xanthan gum was effective in conveying the kelulut honey as a topical preparation without compromising on its antibacterial properties.

\section{Stability Study}

The stability study was conducted according to the $\mathrm{ICH}$ guideline for storage condition, which was performed by keeping the preparation long-term $\left(25^{\circ} \mathrm{C} \pm 2 / 60 \% \pm 5 \mathrm{RH}\right)$ and accelerated storage $\left(40^{\circ} \mathrm{C} \pm 2 / 75 \% \pm 5 \mathrm{RH}\right)$ conditions for six months (World Health Organisation, 2018). The physicochemical properties i.e., colour, homogeneity, $\mathrm{pH}$, and viscosity, and antibacterial efficacy i.e., inhibition zone and formation of bacterial colony, of the optimal preparation was determined at $0,1,2,3$, and 6 months.

The results for the physicochemical properties of the preparation are shown in Table 6 and Figure 4 respectively. The colour, homogeneity, and $\mathrm{pH}$ level after six months of storage remained unchanged. The $\mathrm{pH}$ was measured to be in the range between $3.50 \pm 0.10$ and $3.58 \pm 0.10$ with the difference between the lowest and highest $\mathrm{pH}$ levels was $2 \%$. Based on the results obtained, the physicochemical properties of the optimal preparation were remained unchanged. The ability to maintain the fundamental

Table 5. The results on formation of bacterial colony for (a) Grampositive and (b) Gram-negative bacteria

(a)

\begin{tabular}{lccc}
\hline & \multicolumn{3}{c}{ Formation of bacteria colony } \\
\cline { 2 - 4 } & $\begin{array}{l}\text { Xanthan } \\
\text { gum }\end{array}$ & Comvita & $\begin{array}{c}\text { Control } \\
\text { (broth only) }\end{array}$ \\
\hline & Standard strain & \\
S. aureus ATCC6538 & No & No & Yes \\
S. pyogenes ATCC19615 & No & No & Yes \\
E. faecalis ATCC29212 & No & Yes & Yes \\
\hline & Clinical isolated strain & \\
S. aureus & No & No & Yes \\
S. hominis & No & No & Yes \\
S. pyogenes & No & No & Yes \\
S. agalactiae & No & No & Yes \\
S. haemolyticus & No & No & Yes \\
\hline
\end{tabular}

(b)

\begin{tabular}{lccc}
\hline & \multicolumn{2}{c}{ Formation of bacteria colony } \\
\cline { 2 - 4 } & $\begin{array}{c}\text { Xanthan } \\
\text { gum }\end{array}$ & Comvita & $\begin{array}{c}\text { Control } \\
\text { (broth only) }\end{array}$ \\
\hline E. coli ATCC 8739 & Standard strain & \\
S. typhimurium ATCC14028 & No & No & Yes \\
K. pneumonia ATCCBAA1144 & No & No & Yes \\
P. aeruginosa ATCC27853 & No & No & Yes \\
P. mirabilis ATCC12453 & No & No & Yes \\
\hline & Clinical isolated strain & Yes \\
E. coli & No & No & Yes \\
Salmonella sp. & No & No & Yes \\
K. pneumonia & No & No & Yes \\
$P$. aeruginosa & No & No & Yes \\
E. cloacae & No & No & Yes \\
E. aerogenes & No & No & Yes \\
P. vulgaris & No & No & Yes \\
$P$. mirabilis & No & No & Yes \\
A. baumannii & No & No & Yes \\
\hline
\end{tabular}

Table 6. The results for colour, homogeneity, and $\mathrm{pH}$ during six months stability test for the optimal preparation

\begin{tabular}{|c|c|c|c|c|c|c|c|c|c|c|}
\hline & \multicolumn{5}{|c|}{ (Long term) $25^{\circ} \mathrm{C} \pm 2 / 60 \% \pm 5 \mathrm{RH}$} & \multicolumn{5}{|c|}{ (Accelerated) $40^{\circ} \mathrm{C} \pm 2 / 75 \% \pm 5 \mathrm{RH}$} \\
\hline & \multicolumn{5}{|c|}{ Months } & \multicolumn{5}{|c|}{ Months } \\
\hline & 0 & 1 & 2 & 3 & 6 & 0 & 1 & 2 & 3 & 6 \\
\hline Colour & \multicolumn{5}{|c|}{ Dark brown } & \multicolumn{5}{|c|}{ Dark brown } \\
\hline Homogeneity & \multicolumn{5}{|c|}{ Homogeneous } & \multicolumn{5}{|c|}{ Homogeneous } \\
\hline $\mathrm{pH}$ & $3.52 \pm 0.05$ & $3.50 \pm 0.05$ & $3.51 \pm 0.06$ & $3.57 \pm 0.04$ & $3.56 \pm 0.03$ & $3.57 \pm 0.07$ & $3.52 \pm 0.07$ & $3.53 \pm 0.05$ & $3.58 \pm 0.04$ & $3.56 \pm 0.04$ \\
\hline
\end{tabular}

The symbol \pm represents the standard deviation which was calculated between three biological replicates. 


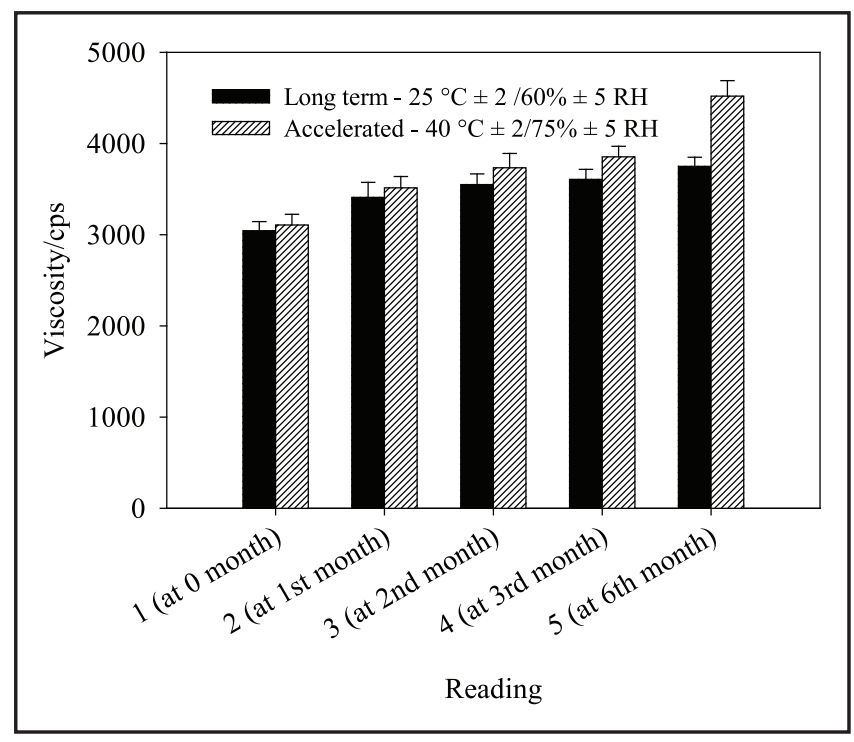

Figure 4. Viscosity of the preparation during the six-month of stability study after been stored at long term $-25^{\circ} \mathrm{C} \pm 2 / 60 \% \pm$ $5 \mathrm{RH}$ and accelerated $-40^{\circ} \mathrm{C} \pm 2 / 75 \% \pm 5 \mathrm{RH}$ storing conditions.

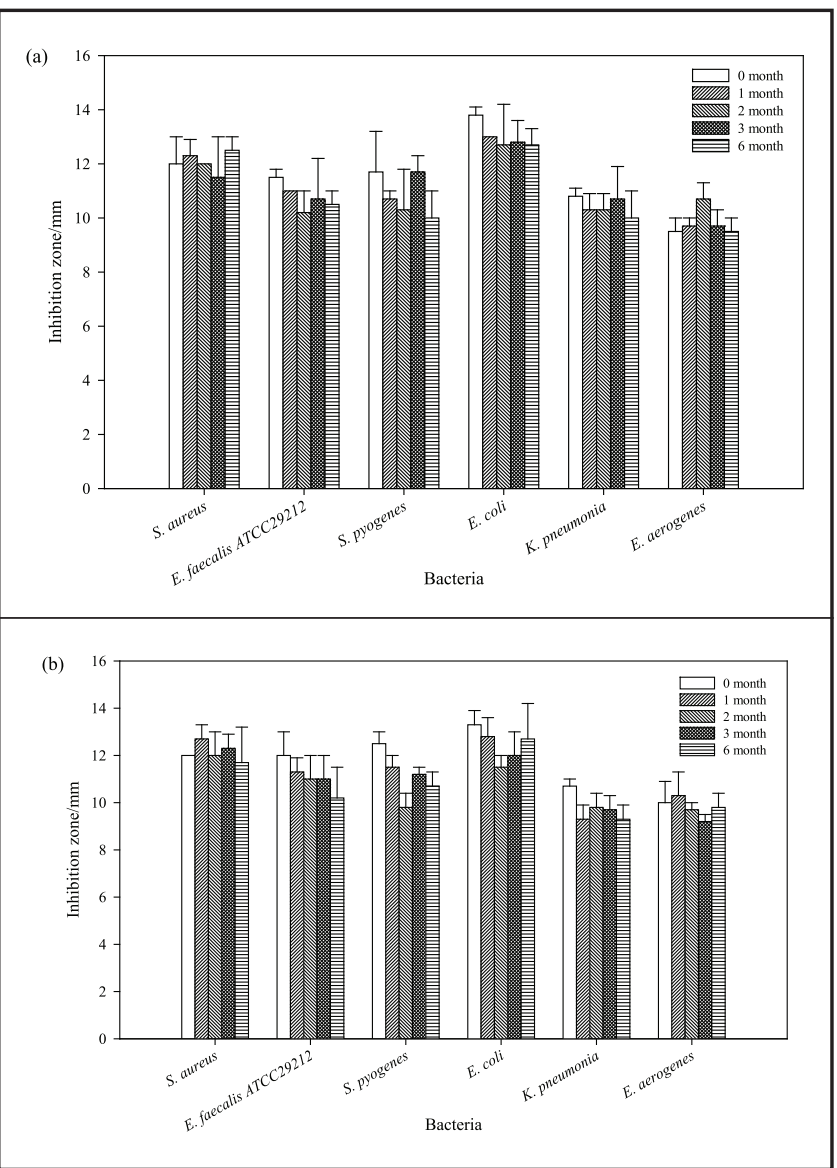

Error bars symbolise the errors calculated from three biological replicates. One sample t-test represent significant differences between the mean of the sampled population and the hypothesised population mean ( $P$-value $<0.05)$.

Figure 5. Measurement of inhibition zone on six bacteria for the optimal preparation after stored in (a) long-term and $25^{\circ} \mathrm{C} \pm 2 / 60 \% \pm 5 \mathrm{RH}$, and (b) accelerated $-40^{\circ} \mathrm{C} \pm 2 / 75 \% \pm 5 \mathrm{RH}$ storage conditions. physicochemical properties indicate acceptable and reliable preparation (Chen et al., 2016).

As for viscosity, the preparation showed a directly proportional relationship with time. The lowest viscosity of $3043 \pm 100.7 \mathrm{cps}$ for the long term and $3107 \pm 116.8 \mathrm{cps}$ for the accelerated storage were recorded at 0 month, respectively. The highest viscosity of $3750 \pm 100.0 \mathrm{cps}$ for the long term and $4520 \pm 170.6 \mathrm{cps}$ for the accelerated storage were recorded after the six months of storage, respectively. The variation in viscosity between 0 month and sixth month was $23 \%$ for the long term and $46 \%$ for the accelerated storage, respectively.

\section{Antibacterial Efficacy}

The antibacterial efficacy of the preparation within the six months of stability study was evaluated through the measurement of inhibition zone and formation of bacterial colony. In both evaluations, six wound-infecting bacteria, which include three Gram-positive (S. aureus, E. faecalis, and S. pyogenes) and three Gram-negative (E. coli, K. pneumonia and $E$. aerogenes) were used. The measurement of the inhibition zone on Gram-positive and Gram-negative bacteria are shown in Figure 5 (a) and Figure 5 (b), respectively followed by the results of the formation of the bacterial colony.

The zone of inhibition showed a variation of $10.7 \%$ within the six-month stability study. The inhibition zones measured were ranged from $9.2 \pm 0.30$ to $13.8 \pm 0.30 \mathrm{~mm}$. As for the formation of bacterial colony, the preparation remained valid to prevent the formation of the bacterial colony within the six months of the stability study (data not shown). Based on the outcomes obtained, the efficacy of the preparation remained effective without deficiency indicating a stable and reliable preparation that can sustain its antibacterial properties over time (Irish et al., 2011).

The synergistic interaction is considered positive if the therapeutic effect that initially present in the preparation remained without interruption. The results indicated that the preparation which prepared in this study are capable to retain the antibacterial properties which proven by the identical inhibition zone and bactericidal effect. The porous structure facilitates uniformed dispersion of honey across the polymeric structure of the preparation may explain the uninterrupted antibacterial properties (Sharma et al., 2015). In addition, the interactions between the charges of the polymeric agent i.e., xanthan gum which loaded with honey and the charges on the surface of the bacterial membrane formed a contact (Kaith et al., 2015) that allow the compounds such as phenolic acids and hydrogen peroxide to promote cell disruption and lysis to kill the bacteria (Henriques et al., 2010, 2011). A similar finding with the positive synergistic effect of honey in preparation that led to more than $95 \%$ of drug release was demonstrated by the previous study (El-kased et al., 2017).

\section{CONCLUSION}

The optimal preparation was finalised at a $\mathrm{pH}$ of 3.5 , the honey concentration of $90 \%(\mathrm{w} / \mathrm{v})$, and xanthan gum concentration of $1.5 \%(\mathrm{w} / \mathrm{v})$. The utilisation of xanthan gum as polymeric agent was fit for preparing kelulut as a topical preparation. Based on the optimal preparation, the preparation demonstrated reliable physicochemical properties, and most importantly, the potent antibacterial properties, i.e., bactericidal effect, were retained after the honey was converted to a topical preparation. This was supported by constant viscosity and efficacy of the 
preparation within six months of stability study indicating stable and reliable preparation.

\section{ACKNOWLEDGEMENT}

The authors would like to acknowledge Centre of Excellence for Advanced Research in Fluid Flow, Universiti Malaysia Pahang in providing the research facilities and fund for this project under the RDU190357 and RDU1703111. In addition, special thanks and gratitude to the Sultan Ahmad Shah Medical Centre for providing the clinical bacterial strains.

\section{Conflict of Interests}

The authors declare that they have no conflict of interests.

\section{REFERENCES}

Almasaudi, S.B., Al-nahari, A.A.M., Abd El-Ghany, E.S.M., Barbour, E., Al Muhayawi, S. M., Al-jaouni, S. \& Harakeh, S. (2017). Antimicrobial effect of different types of honey on Staphylococcus aureus. Saudi Journal of Biological Sciences 24: 1255-1261. https://doi.org/10.1155/2016/3643824

Ammer, R.M., Zaman, S., Khalid, M., Bilal, M., Erum, S., Huang, D. \& Che, S. (2016). Optimization of antibacterial activity of Eucalyptus tereticornis leaf extracts against Escherichia coli through response surface methodology. Journal of Radiation Research and Applied Sciences 9: 376-385. https:// doi.org/10.1016/j.jrras.2016.05.001

Anitha, G. \& Pandey, V.P. (2016). Review on: Statistical designs and response surface methodology (RSM) as a tool for the optimization of HPLC Methods. International Journal of Pharmacy and Analytical Research 5: 552-569.

Badwaik, H.R., Giri, T.K., Nakhate, K.T., Kashyap, P. \& Tripathi, D.K. (2013). Xanthan gum and its derivatives as a potential bio-polymeric carrier for drug delivery system. Current Drug Delivery 10: 587-600. https://doi.org/10.2174/ 1567201811310050010

Bakar, M.F.A., Sanusi, S.B., Bakar, F.I.A., Cong, O.J. \& Mian, Z. (2017). Physicochemical and antioxidant potential of raw unprocessed honey from Malaysian stingless bees. Pakistan Journal of Nutrition 16: 888-894. https://doi.org/ 10.3923/pjn.2017.888.894

Benny, I.S., Gunasekar, V. \& Ponnusami, V. (2014). Review on application of xanthan gum in drug delivery. International Journal of PharmTech Research 6: 1322-1326.

Boukraâ, L. (2014). Honey in traditional and modern medicine. New York, United States: Taylor \& Francis Group. https:// doi.org/10.1201/b15608

Brudzynski, K. \& Sjaarda, C. (2014). Antibacterial compounds of Canadian honeys target bacterial cell wall inducing phenotype changes, growth inhibition and cell lysis that resemble action of $\beta$-Lactam antibiotics. PLOS ONE 9: e106967. https://doi.org/10.1371/journal.pone.0106967.g003

Bueno, V.B., Bentini, R., Catalani, L.H. \& Petri, D.F.S. (2013). Synthesis and swelling behavior of xanthan-based hydrogels. Carbohydrate Polymers 92: 1091-1099. https:// doi.org/10.1016/j.carbpol.2012.10.062

Carter, D.A., Blair, S.E., Cokcetin, N.N., Bouzo, D., Brooks, P., Schothauer, R. \& Harry, E.J. (2016). Therapeutic manuka honey: no nonger so alternative. Frontiers in Microbiology 7: 569. https://doi.org/10.3389/fmicb.2016.00569

Chen, M.X., Alexander, K.S. \& Baki, G. (2016). Formulation and evaluation of antibacterial creams and gels containing metal ions for topical application. Journal of Pharmaceutics. 2016: 5754349. https://doi.org/10.1155/2016/5754349
Chua, L.S. \& Ismail, N.I.M. (2015). Anti-inflammatory and antimicrobial activities of selected honey samples. Asian Journal of Agricultural Research 9: 293-304. https://doi.org/ 10.3923/ajar.2015.293.304

Cotter, P.D. \& Hill, C. (2003). Surviving the acid test: responses of Gram-positive bacteria to low $\mathrm{pH}$. Microbiology and Molecular Biology Reviews 67: 429-453. https://doi.org/ 10.1128/MMBR.67.3.429-453.2003

Cunha, P.L.R., Castro, R.R., Rocha, F.A.C., Paula, R.C.M. De \& Feitosa, J.P.A. (2005). Low viscosity hydrogel of guar gum: preparation and physicochemical characterization. International Journal of Biological Macromolecules 37: 99-104. https://doi.org/10.1016/j.ijbiomac.2005.09.001

Dantas, M.G.B., Reis, S.A.G., Damasceno, C.M.D., Rolim, L.A., Rolim-neto, P.J., Carvalho, F.O., Quintans-Junior, L.J. \& Almeida, J.R.G. da S. (2016). Development and evaluation of stability of a gel formulation containing the monoterpene borneol. The Scientific World Journal 2016: 7394685. https:// doi.org/10.1155/2016/7394685

Dewanjee, S., Maiti, A., Majumdar, R., Majumdar, A. \& Mandal, S.C. (2008). Evaluation of antimicrobial activity of hydroalcoholic extract Schima wallichii bark. Pharmacologyonline 1: 523-528.

Dimeski, G., Solano, C., Petroff, M.K. \& Hynd, M. (2011). Centrifugation protocols: tests to determine optimal lithium heparin and citrate plasma sample quality. Annals of Clinical Biochemistry 48: 218-222. https://doi.org/10.1258/ acb.2010.010230

Dluya, T. (2016). Critical review: antioxidant properties and antibiotic mechanism of honey against infectious diseases. International Journal of Advances in Life Science and Technology 2: 16-24. https://doi.org/10.18488/ journal.72/2015.2.2/72.2.16.24

El-kased, R.F., Amer, R.I., Attia, D. \& Elmazar, M.M. (2017). Honey-based hydrogel: in vitro and comparative in vivo evaluation for burn wound healing. Scientific Reports 7: 9692. https://doi.org/10.1038/s41598-017-08771-8

Franklin, R.C., Matthew, A.W., Jeff, A., Michael, N.D., George, M.E., Mary, J.F., Hardy, D.J., Hecht, D.W., Hindler, J.A. \& Patel, J.B. (2012). Methods for dilution antimicrobial susceptibility tests for bacteria that grow aerobically: Approved standard - Ninth Edition (Vol. 32). Wayne, USA. Retrieved from https://mafiadoc.com/download/methodsfor-dilution-antimicrobial-susceptibility-tests_5a19a8801723dd4f2ac359bc.html

Garcia-Ochoa, F., Santos, V.E., Casas, J.A. \& Gomez, E. (2000). Xanthan gum: production, recovery, and properties. Biotechnology Advances 18: 549-579. https://doi.org/10.1016/ S0734-9750(00)00050-1

Grego, E., Robino, P., Tramuta, C., Giusto, G., Boi, M., Colombo, R., Serra, G., Chiado-Cutin, S., Gandini, M. \& Nebbia, P. (2016). Evaluation of antimicrobial activity of Italian honey for wound healing application in veterinary medicine. Schweizer Archiv Fur Tierheilkunde 158: 521-527. https:// doi.org/10.17236/sat00075

Hemendrasinh, J.R. \& Dhruti, P.M. (2015). A review on pharmaceutical gel. International Journal of Pharmaceutical Sciences 1: 33-47.

Henriques, A.F., Jenkins, R.E. \& Burton, N.F. (2010). The intracellular effects of manuka honey on Staphylococcus aureus. European Journal of Clinical Microbiology \& Infectious Diseases 29: 45-50. https://doi.org/10.1007/s10096-009-08172 
Henriques, A.F., Jenkins, R.E. \& Burton, N.F. (2011). The effect of manuka honey on the structure of Pseudomonas aeruginosa. European Journal of Clinical Microbiology \& Infectious Diseases 30: 167-171. https://doi.org/10.1007/ s10096-010-1065-1

Iradhati, A.H. \& Jufri, M. (2017). Formulation and physical stability test of Griseofulvin microemulsion gel. International Journal of Applied Pharmaceutics 9: 7-10. https:// doi.org/10.22159/ijap.2017.v9s1.22_27

Irish, J., Blair, S. \& Carter, D.A. (2011). The antibacterial activity of honey derived from Australian flora. PLoS One 6: e18229. https://doi.org/10.1371/journal.pone.0018229

Ismail, W.I.W. (2016). A review on beekeeping in Malaysia history, importance and future direction. Journal of Sustainability Science and Management 11: 70-80.

Jain, S., Rathod, N., Nagi, R., Sur, J., Laheji, A., Gupta, N., Agrawai, P. \& Prasad, S. (2016). Antibacterial effect of aloe vera gel against oral pathogens: An in-vitro study. Journal of Clinical and Diagnostic Research 10: 41-44. https://doi.org/ 10.7860/JCDR/2016/21450.8890

Jalil, M.A.A., Kasmuri, A.R. \& Hadi, H. (2017). Stingless bee honey, the natural wound healer: a review. Skin Pharmacology and Physiology 30: 66-75. https://doi.org/10.1159/ 000458416

Jefferson, K.K. (2004). What drives bacteria to produce a biofilm? FEMS Microbiology Letters 236: 163-173. https:// doi.org/10.1111/j.1574-6968.2004.tb09643.x

Johnston, M., McBride, M., Dahiya, D., Owusu-apenten, R. \& Nigam, P.S. (2018). Antibacterial activity of Manuka honey and its components: an overview. AIMS Microbiology 4: 655664. https://doi.org/10.3934/microbiol.2018.4.655

Jones, E.M., Cochrane, C.A. \& Percival, S.L. (2015). The effect of $\mathrm{pH}$ on the extracellular matrix and biofilms. Advances in Wound Care 4: 431-439. https://doi.org/10.1089/wound. 2014.0538

Kaith, B.S., Sharma, R. \& Kalia, S. (2015). Guar gum based biodegradable, antibacterial and electrically conductive hydrogels. International Journal of Biological Macromolecules 75: 266-275. https://doi.org/10.1016/j.ijbiomac.2015.01.046

Kateel, R., Bhat, G., Baliga, S., Augustine, A.J., Ullal, S. \& Adhikari, P. (2018). Antibacterial action of tropical honey on various bacteria obtained from diabetic foot ulcer. Complementary Therapies in Clinical Practice 30: 29-32. https://doi.org/10.1016/j.ctcp.2017.11.001

Khalil, A.T., Khan, I., Ahmad, K., Khan, Y.A., Khan, J. \& Shinwari, Z. K. (2014). Antibacterial activity of honey in north-west Pakistan against select human pathogens. Journal of Traditional Chinese Medicine 34: 86-89. https://doi.org/ 10.1016/s0254-6272(14)60059-5

Khuri, A.I. (2017). Response Surface Methodology and Its Applications In Agricultural and Food Sciences. Biometric and Biostatics International Journal 5: 1-11. https://doi.org/ 10.15406/bbij.2017.05.00141

Kim, C., Wilkins, K., Bowers, M., Wynn, C. \& Ndegwa, E. (2018). Influence of $\mathrm{pH}$ and temperature on growth characteristics of leading foodborne pathogens in a laboratory medium and select food beverages. Austin Food Sciences 3: 1031.

Liu, J., Ye, Y., Lin, T., Wang, Y. \& Peng, C. (2013). Effect of floral sources on the antioxidant, antimicrobial, and antiinflammatory activities of honeys in Taiwan. Food Chemistry 139: 938-943. https://doi.org/10.1016/j.foodchem. 2013.02.015
Lu, J., Turnbull, L., Burke, C.M., Liu, M., Carter, D.A., Schlothauer, R.C., Whitchurch, C.B. \& Harry, E.J. (2014). Manuka-type honeys can eradicate biofilms produced by Staphylococcus aureus strains with different biofilm-forming abilities. Peer J 2: 1-25. https://doi.org/10.7717/peerj.326

Madiha, I.Y., Rukayadi, Y. \& Norhayati, H. (2017). Effects of extraction conditions on yield, total phenolic contents and antibacterial activity of methanolic Cinnamomum zeylanicum blume leaves extract. International Food Research Journal 24: 779-786.

Majumdar, S., Roy, S., Gupta, R. \& Khatun, N. (2018). Strategy for improving skin permeation by using topical nanoparticulate gel of aloe vera and in-vivo evaluation using wistar rats. International Journal of Scientific and Research Publications 8: 323-339.

Mohd-aspar, M.A.S. \& Edros, R.Z. (2019). Antibacterial properties of kelulut, tualang and acacia honey against wound-infecting bacteria. Journal of Tropical Agricultural Science 42: 1185-1208.

Mohd-aspar, M.A.S., Edros, R.Z. \& Hamzah, N.A. (2021). Optimisation and evaluation of antibacterial topical preparation from Malaysian kelulut honey using guar gum as polymeric agent. Pertanika Journal of Science and Technology 29: 565-592.

Mohd, M., Edros, R. \& Hamzah, N.A. (2020a). Antibacterial evaluation of Malaysian Kelulut, Tualang and Acacia honey against wound infecting bacteria. In IOP Conference Series: Materials Science and Engineering. https://doi.org/ 10.1088/1757-899X/991/1/012065

Mohd, M., Edros, R. \& Hamzah, N.A. (2020b). Antibacterial properties of Kelulut, Tualang and Acacia honey against fourteen clinically-isolated strains of bacteria-infecting wound. In AIP Conference Proceedings 2252.

Molan, P. (1992). The antibacterial activity of honey. 1 . The nature of the antibacterial activity. Bee World 73: 5-28. https://doi.org/10.1080/0005772X.1992.11099109

Moussa, A., Noureddine, D., Mohamed, H.S. \& Abdelmelek, M. (2012). Antibacterial activity of various honey types of Algeria against Staphylococcus aureus and Streptococcus pyogenes. Asian Pacific Journal of Tropical Medicine 5: 773776. https://doi.org/10.1016/S1995-7645(12)60141-2

Mulye, S.P., Wadkar, K.A. \& Kondawar, M.S. (2014). Formulation development and evaluation of Indomethacin emulgel. Pelagia Research Library 4: 31-45.

Negut, I., Grumezescu, V. \& Grumezescu, A.M. (2018). Treatment strategies for infected wounds. Molecules 23: 2392. https:/ /doi.org/10.3390/molecules23092392

Pande, V., Patel, S., Patil, V. \& Sonawane, R. (2014). Design expert assisted formulation of topical bioadhesive gel of Sertaconazole Nitrate. Advanced Pharmaceutical Bulletin 4: 121-130. https://doi.org/10.5681/apb.2014.019

Panther, D.J. \& Jacob, S.E. (2015). The importance of acidification in atopic eczema: an underexplored avenue for treatment. Journal of Clinical Medicine 4: 970-978. https://doi.org/10.3390/jcm4050970

Peacock, S.J. \& Paterson, G.K. (2015). Mechanisms of Methicillin Resistance in Staphylococcus aureus. Annual Review of Biochemistry 84: 577-601. https://doi.org/10.1146/ annurev-biochem-060614-034516

Pongsavee, M. (2015). Effect of sodium benzoate preservative on micronucleus induction, chromosome break, and Ala40Thr superoxide dismutase gene mutation in lymphocytes. Biomedical Research International 2015: 103512. https://doi.org/10.1155/2015/103512 
Ranneh, Y., Ali, F., Zarei, M., Akim, A. \& Abd, H. (2018). Malaysian stingless bee and tualang honeys: A comparative characterization of total antioxidant capacity and phenolic profile using liquid chromatography-mass spectrometry. LWT - Food Science and Technology 89: 1-9. https://doi.org/ 10.1016/j.Iwt.2017.10.020

Sanchez-Maldonado, A.F., Schieber, A. \& Ganzle, M.G. (2011). Structure-function relationships of the antibacterial activity of phenolic acids and their metabolism by lactic acid bacteria. Journal of Applied Microbiology 111: 1176-1184. https://doi.org/10.1111/j.1365-2672.2011.05141.x

Schmid-wendtner, M.H. \& Korting, H.C. (2006). The pH of the skin surface and its impact on the barrier function. Skin Pharmocology and Physiology 19: 296-302. https://doi.org/ $10.1159 / 000094670$

Serra, R., Grande, R., Butrico, L., Rossi, A., Francesco, U., Settimio, U.F., Caroleo, B., Amato, B., Gallelli, L. \& Franciscis, S.de. (2015). Chronic wound infections: the role of Pseudomonas aeruginosa and Staphylococcus aureus. Expert Review of Anti-Infective Therapy 13: 605-613. https:// doi.org/10.1586/14787210.2015.1023291

Shagana, J. A. \& Geetha, R. (2017). Comparative analysis of antimicrobial activity of black tea, green tea and white Tea extracts on Streptococcus mutans by tube dilution method. Journal of Pharmaceutical Sciences and Research 9: 1581-1582.

Shahmihammadi, M., Javadi, M. \& Nassiri-asl, M. (2016). An overview on the effects of sodium benzoate as a preservative in food products. Biotechnology and Health Sciences 3. https://doi.org/10.17795/bhs-35084

Shahzad, Y., Afreen, U., Shah, S.N.H. \& Hussain, T. (2012). Applying response surface methodology to optimize nimesulide permeation from topical formulation. Pharmaceutical Development and Technology 18: 1391-1398. https:// doi.org/10.3109/10837450.2012.723721

Sharma, R., Kaith, B.S., Kalia, S., Pathania, D., Kumar, A., Sharma, N., Street, R.M. \& Schauer, C. (2015). Biodegradable and conducting hydrogels based on Guar gum polysaccharide for antibacterial and dye removal applications. Journal of Environmental Management 162: 37-45. https://doi.org/10.1016/j.jenvman.2015.07.044

Shekar, P., Kumar, K.S., Jabasingh, S.A., Radhakrishnan, M. \& Balagurunathan, R. (2014). Optimization of medium components for antibacterial metabolite production from marine streptomyces sp. PUA2 using response surface methodology. International Journal of Pharmacy and Pharmaceutical Sciences 6: 6-11.

Sherlock, O., Dolan, A., Athman, R., Power, A., Gethin, G., Cowman, S. \& Humphreys, H. (2010). Comparison of the antimicrobial activity of Ulmo honey from Chile and Manuka honey against methicillin-resistant Staphylococcus aureus, Escherichia coli and Pseudomonas aeruginosa. BMC Complementary and Alternative Medicine 10: 47. https:// doi.org/10.1186/1472-6882-10-47

Singh, M.P., Nagori, B.P., Shaw, N.R., Tiwari, M. \& Jhanwar, B. (2013). Formulation development \& evaluation of topical gel formulations using different gelling agents and its comparison with marketed gel formulation. International Journal of Pharmaceutical Erudition 3: 1-10.
Sousa, J.M., Souza, E.L.De, Marques, G., Meireles, B., Cordeiro, A.T.D.M., Gullón, B., Pintado, M.M. \& Magnani, M. (2016). Polyphenolic profile and antioxidant and antibacterial activities of monofloral honeys produced by Meliponini in the Brazilian semiarid region. Food Research International 84: 61-68. https://doi.org/10.1016/j.foodres.2016.03.012

Syazana, N., Gan, S.H. \& Sukari, A. (2013). Analysis of volatile compounds of Malaysian tualang honey using gas chromatography mass spectrometry. African Journal Traditional Complement Alternative Medicine 10: 180-188. https://doi.org/10.4314/ajtcam.v10i2.2

Tan, H.T., Rahman, R.A., Gan, S.H., Halim, A.S., Hassan, S.A., Sulaiman, S.A. \& Bs, K. (2009). The antibacterial properties of Malaysian tualang honey against wound and enteric microorganisms in comparison to manuka honey. $B M C$ Complementary and Alternative Medicine 34: 34. https:// doi.org/10.1186/1472-6882-9-34

Thombare, N., Jha, U., Mishra, S. \& Siddiqui, M.Z. (2016). Guar gum as a promising starting material for diverse applications: a review. International Journal of Biological Macromolecules 88: 361-372. https://doi.org/10.1016/ j.ijbiomac.2016.04.001

Tuksitha, L., Chen, Y.S., Chen, Y., Wong, K. \& Peng, C. (2018). Antioxidant and antibacterial capacity of stingless bee honey from Borneo (Sarawak). Journal of Asia-Pacific Entomology 21: 563-570. https://doi.org/10.1016/j.aspen. 2018.03.007

Wang, Y., Fang, X., An, F., Wang, G. \& Zhang, X. (2011). Improvement of antibiotic activity of Xenorhabdus bovienii by medium optimization using response surface methodology. Microbial Cell Factories 10: 98. https://doi.org/ 10.1186/1475-2859-10-98

Weston, R.J., Mitchell, K.R. \& Allen, K.L. (1999). Antibacterial phenolic components of New Zealand manuka honey. Food Chemistry 64: 295-301. https://doi.org/10.1016/S03088146(98)00100-9

Wong, R.S.H., Ashton, M. \& Dodou, K. (2015). Effect of crosslinking agent concentration on the properties of unmedicated hydrogels. Pharmaceutics 7: 305-319. https://doi.org/10.3390/pharmaceutics 7030305

World Health Organisation. (2018). WHO expert committee on specification for pharmaceutical preparations. Geneva, Switzerland.

Yaacob, M., Rajab, N.F., Shahar, S. \& Sharif, R. (2018). Stingless bee honey and its potential value: a systematic review. Food Research 2: 124-133. https://doi.org/10.26656/ fr.2017.2(2).212

Zainol, M.I., Yusoff, K.M., Yasim, M. \& Yusof, M. (2013). Antibacterial activity of selected Malaysian honey. BMC Complementary and Alternative Medicine 13: 129. https:// doi.org/10.1186/1472-6882-13-129

Zakaria, A.S. (2015). Mechanism of antibacterial action of honey on pathogenic wound bacterial strains: a proteomic analysis. International Research Journal of Pharmacy 6: 778788. https://doi.org/10.7897/2230-8407.0611151

Zhu, T., Mao, J., Cheng, Y., Liu, H., Lv, L., Ge, M., Li, S., Huang, J., Chen, Z. \& Li, H. (2019). Recent progress of polysaccharidebased hydrogel interfaces for wound healing and tissue engineering. Advanced Materials Interfaces 6: 1-22. https:// doi.org/10.1002/admi.201900761. 